\title{
A Study of Possible Separable Solutions for Plasma Transport in Ohmically Heated Tokamaks
}

Taner Uckan

\section{OAK RIDGE NATIONAL LABORATORY}




\section{DISCLAIMER}

This report was prepared as an account of work sponsored by an agency of the United States Government. Neither the United States Government nor any agency Thereof, nor any of their employees, makes any warranty, express or implied, or assumes any legal liability or responsibility for the accuracy, completeness, or usefulness of any information, apparatus, product, or process disclosed, or represents that its use would not infringe privately owned rights. Reference herein to any specific commercial product, process, or service by trade name, trademark, manufacturer, or otherwise does not necessarily constitute or imply its endorsement, recommendation, or favoring by the United States Government or any agency thereof. The views and opinions of authors expressed herein do not necessarily state or reflect those of the United States Government or any agency thereof. 


\section{DISCLAIMER}

Portions of this document may be illegible in electronic image products. Images are produced from the best available original document. 
Printed in the United States of America. Available from National Technical Information Service

U.S. Department of Commerce

5285 Port Royal Road, Springfield, Virginia 22161

Price: Printed Copy $\$ 4.50$; Microfiche $\$ 3.00$

This report was prepared as an account of work sponsored by an agency of the United States Government. Neither the United States Government nor any agency thereof, nor any of their employees, contractors, subcontractors, or their employees, makes any warranty, express or implied, nor assumes any legal liability or responsibility for any third party's use or the results of such use of any information, apparatus, product or process disclosed in this report, nor represents that its use by such third party would not infringe privately owned rights. 
Contract No. W-7405-eng-26

FUSION ENERGY DIVISION

A STUDY OF POSSIBLE SEPARABLE SOLUTIONS FOR PLASMA

TRANSPORT IN OHMICALLY HEATED TOKAMAKS

Taner Uckan

Date Published - October 1977

NOTICE I hị document contains information of a preilminary natupe. It is subject to revision or correction and therefore does not represent a final report.

Prepared by the

OAK RIDGE NATIONAL LABORATORY

Oak Ridge, Tennessee 37830 operated by UNION CARBIDE CORPORATION for the DEPARTMENT OF ENERGY

This report was prepared as an account of work sponeorod by the Unitod States Government. Noither Research and Development Administration, nor any of their employees, nor any of their contractors, subcontractors, or their employecs, makes any wartanty, express of implied, or assumes any lega kability of responsibility for the accujacy, completeness of usefulnes of any information, apparatus, product or prosiss disclosed, or represents, hapt its use would not 


\begin{abstract}
The transport problem for an ohmically heated tokamak plasma is investigated analytically with the separation of the variables time, $t$, and $\rho=r^{2} h(t)$, where $r$ is the space coordinate and $h(t)$ is only a function of time. This investigation examines the circumstances under which these analytical solutions are possible. The time evolution of the current density and temperature profiles is then obtained for a simple plasma model which includes the electric field diffusion and heat conduction losses. Expressions are also given for plasma discharge parameters such as the time evolution of the safety factor, the plasma current, the poloidal flux function, the skin time, the poloidal beta, the transformer flux, and the electron energy lifetime. The results are then applied to a typical size tokamak device.
\end{abstract}




\section{INTRODUCTION}

The objective of this work is to investigate the plasma transport problem for an ohmically heated tokamak by invoking the separation of variables. ${ }^{1}$ This leads to analytical solutions for the temperature and current density profiles as a function of time and $\rho=r^{2} h(t)$, where $h(t)$ is a function of time only. These solutions are possible under special conditions which are discussed later. The separation of variables technique used here eventually provides a quick, easy solution to the problem without the need to solve a more sophisticated transport problem with a large computer code. Also, this method is capable of evaluating the time behavior of the plasma discharge parameters in the early stage of the heating process.

This paper is organized as follows: Sect. 2 summarizes the plasma model and the basic equations, Sect. 3 outlines the separation of variables technique and the means of obtaining the resulting equations, and Sect. 4 presents the time evolution of the discharge parameters in terms of the system parameters. General discussions and an application of the results are included in sect. 5 . 
2. PHYSICS MODEL AND BASIC EQUATIONS

The transport problem for a toroldally confined plasma possessês many mathematical complexities. In order to avoid these difficulties, we assume a cylindrical plasma which is a reasonable approximation of the large aspect ratio devices. Furthermore, for the sake of simplicity, the following assumptions are adopted for the model.

(1) The plasma density is uniform and constant.

(2) The plasma ion density $n_{i}$ is equal to the electron density $\mathrm{n}_{e}$ and $\mathrm{n} \equiv \mathrm{n}_{\mathrm{e}}=\mathrm{n}_{\mathrm{i}}$.

(3) $z_{\text {eff }}$ is assumed to be unity.

(4) The electron and ion temperatures are equal, i.e., $\mathrm{T}_{\mathrm{e}}=\mathrm{T}_{\mathbf{i}}=\mathrm{T}$.

(5) The charge exchange, ionization, radiation, and convection losses are neglected. The ion heat conduction losses are ignored.

(6) The electrical conductivity $\sigma$ is classical.

The basic equations are as follows. (The mks system of units is used.)

$$
\begin{aligned}
& \frac{\partial E}{\partial r}=\frac{\partial B_{p}^{\prime}}{\partial t}, \\
& \mu J=\frac{1}{r} \cdot \frac{\partial}{\partial r}\left(\mathrm{rB}_{\mathrm{p}}\right), \\
& J=\sigma E \\
& \sigma=k \mathrm{~T}^{3 / 2}, \\
& 3 \mathrm{n} \frac{\partial \mathrm{T}}{\partial \mathrm{t}}=\frac{\mathrm{J}^{2}}{\sigma}=\frac{1}{r} \frac{\partial}{\partial r}\left(\mathrm{rq}_{\mathrm{r}}\right),
\end{aligned}
$$

where

$$
q_{r}=-n \chi \frac{\partial T}{\partial r}
$$


is the electron heat conduction flux, E denotes the toroidal electric rleld,

$$
B_{p}(r, t)=\mu I(r, t) / 2 \pi r
$$

is the induced poloidal magnetic field $\left(\mu=4 \pi \times 10^{-7} \mathrm{H} / \mathrm{m}\right)$, and

$$
I(r, t)=2 \pi \int_{0}^{r} d r^{\prime} r^{\prime} J\left(r^{\prime}, t\right)
$$

is the plasma current. For the thermal conductivity coefficient $\chi$, we introduce a general form

$$
x(r, t)=\operatorname{cn}^{\gamma} r^{2 s} / I^{P} T^{q / 2}
$$

Here, $C$ is a dimensional numerical factor and the values of $\gamma, s, p$, and $q$ are determined 1ater.

As in Ref. 1, the analytical solutions of the problem may be possible in terms of two separable variables, $t$ and $\rho=r^{2} h(t)$, where $h(t)$ is a function of $t$ only and its explicit form will be determined. In Sect. 3, we investigate the conditions under which separable solutions are possible for $T$ and $J$. The set of necessary equations for the problem then follows. 
3. CALCULATIONAL MODEL AND SEPARATION OF VARIABLES

The current density may be written in the form

$$
J(r, t)=J_{f}\left(\frac{t}{\tau}\right)^{\alpha} F(p)
$$

where $J_{f} \equiv J(r=0, t=\tau), F(\rho=0)=1$, and the value of $\tau$ (which is a constant) will be determined. Equation (8) then yields

$$
I(r, t)=\frac{\pi J_{f}}{h(t)}\left(\frac{t}{\tau}\right)^{\alpha} Z(\rho),
$$

where

$$
F(\rho)=\frac{d Z(\rho)}{d \rho}
$$

In turn Eq. (7) becomes

$$
r B_{p}(r, t)=\mu \frac{J_{f}}{2 h(t)}\left(\frac{t}{\tau}\right)^{\alpha} Z(\rho) .
$$

Making use of the variable transformation, combining Eqs. (1) and (2), and applying the separable solutions to the resulting equation, we get

$$
4 \rho \frac{d^{2}}{d \rho^{2}}\left(\frac{F}{\sigma_{2}}\right)+4 \frac{d}{d \rho}\left(\frac{F}{\sigma_{2}}\right)=F\left(C_{1}+C_{2} \rho \frac{d F}{d \rho}\right),
$$

where

$$
\begin{aligned}
\sigma(r, t) & =\sigma_{1}(t) \sigma_{2}(\rho)=k T^{3 / 2}(r, t), \\
C_{1} & \equiv \frac{\mu}{h} \frac{\sigma_{1}}{J_{1}} \frac{d J_{1}}{d t}=\text { constant, }
\end{aligned}
$$




$$
\begin{aligned}
& \mathrm{C}_{2} \equiv \frac{\mu}{\mathrm{li}^{2}} \frac{\mathrm{dh}}{\mathrm{dL}} \sigma_{1}=\text { constant, } \\
& \mathrm{J}_{1} \equiv \mathrm{J}_{\mathrm{f}}\left(\frac{\mathrm{t}}{\tau}\right)^{\alpha} .
\end{aligned}
$$

We now go back to the energy balance equation, Eq. (5). After the variable transformation, it reads

$$
3 n\left(\frac{d T}{d \tau}+\frac{\rho}{h} \frac{d h}{d t} \frac{d T}{d \rho}\right)=\frac{J^{2}}{\sigma}+4 n h x\left(\frac{d T}{d \rho}+\frac{1}{x} \frac{d x}{d \rho} \frac{d T}{d \rho}+\frac{d^{2} T}{d \rho^{2}}\right) \text {. }
$$

Using Eq. (9) in the above relation and imposing the separability requirement, one finds

$$
\begin{aligned}
\rho \frac{d T_{2}}{d \rho}=\frac{F^{2}}{3 n k T_{2}^{3 / 2}} C_{3}-C_{4} T_{2} & +\frac{4 C n^{\gamma}}{3\left(\pi J_{f}\right)^{p}} h_{f}^{(p-s+1)} \\
& \times\left(\frac{l}{\tau}\right) T_{f}^{-q / 2}\left(\frac{t}{\tau}\right)^{\delta} \frac{d}{d \rho}\left(\rho T_{2} P\right)
\end{aligned}
$$

where

$$
\begin{aligned}
\mathrm{P}(\rho) & =\rho^{\mathrm{s}} / \mathrm{Z}^{\mathrm{P}_{\mathrm{T}}^{\mathrm{q}} / 2}, \\
\mathrm{C}_{3} & \equiv \mathrm{J}_{1}^{2} / \mathrm{T}_{1}^{\mathrm{t} / 2} \text { ln } \mathrm{h}=\text { constant, } \\
\mathrm{C}_{4} & \equiv \frac{\partial}{\partial \mathrm{t}} \ln \mathrm{T}_{1} / \frac{\partial}{\partial \mathrm{t}} \ln \mathrm{h}=\text { constant, } \\
\delta & \equiv \ell(p-\mathrm{s}+1)+1-\mathrm{mq} / 2-\mathrm{p} \alpha,
\end{aligned}
$$

and

$$
T(r, t)=T_{1}(t) T_{2}(p)
$$


We may now set

$$
h(t)=h_{f}\left(\frac{t}{\tau}\right)^{l} \text {, }
$$

and

$$
T_{1}(t)=T_{f}\left(\frac{t}{\tau}\right)^{m}
$$

From Eqs. (20), (21), and (24) and $J_{l}=J_{f}(t / \tau)^{\alpha}$, we find

$$
\mathrm{C}_{4} / \mathrm{C}_{3}=(\mathrm{m} / \tau)\left(\mathrm{T}_{\mathrm{f}}^{5 / 2} / \mathrm{J}_{\mathrm{f}}^{2}\right)(\mathrm{t} / \tau)^{(5 \mathrm{~m}-2) / 2-2 \alpha}
$$

and since $C_{4} / C_{3}$ is a constant,

$$
\mathrm{m}=2(1+2 \alpha) / 5 \text {. }
$$

Similarly, Eqs. (16) and (17) yield

$$
\begin{aligned}
& \ell=-2(1-3 \alpha) / 5, \\
& \tau=\mu \sigma_{\mathrm{f}}^{3 / 2} \alpha / \mathrm{h}_{\mathrm{f}},
\end{aligned}
$$

where $\sigma_{f}=\mathrm{kT}_{\mathrm{f}}^{3 / 2}$ and $\mathrm{C}_{1}=1$. This in turn leads us to

$$
\mathrm{C}_{4}=\ldots(1+2 \alpha) /(1-3 \alpha),
$$

and

$$
\mathrm{C}_{4} / \mathrm{C}_{3}=2(1+2 \alpha) \mathrm{T}_{\mathrm{f}}^{5 / 2} / 5 \tau \mathrm{J}_{\mathrm{f}}^{2}
$$

Now, let us go back to Eq. (18). Requiring this to be only a function of $\rho$ yields $\delta=0$, or

$$
\alpha(6-6 s+p-2 q)+3-2 p+2 s-q=0 \text {. }
$$


Therefore, in order to have separable solutions in $t$ and $\rho$, the relation in Eq. (30) must be satisfied. For an arbitrary value of $\alpha$, this relation reduces to

$$
\begin{aligned}
& 5 q+10 s=15, \\
& 6 s+2 q-6=p .
\end{aligned}
$$

Under the separability condition, Eq. (30), we get

$$
x(r, t)=\frac{C_{n}^{\gamma}}{\left(\pi J_{F}\right)^{P}} \frac{h_{L}^{(p-s)}}{T_{F}^{q / 2}}\left(\begin{array}{c}
t \\
\tau
\end{array}\right)^{-3(1+2 \alpha) / 5} P(\rho)
$$

where

$$
\begin{gathered}
P(\rho)=\rho^{s} / Z^{p_{G}^{q / 2},} \\
T(r, t)=T_{f}\left(\frac{t}{\tau}\right)^{2(1+2 \alpha) / 5} G(\rho),
\end{gathered}
$$

and here $T_{f} \equiv T(r=0, t=\tau)$.

Equation (17) may now be rewritten as

$$
A \frac{d S}{d \rho}=D G-F^{2} G^{-3 / 2}-D \frac{(1-3 \alpha)}{(1+2 \alpha)} \rho \frac{d G}{d \rho}
$$

where

$$
\begin{aligned}
& D=\frac{6}{5} \frac{(1+2 \alpha)}{\alpha} \mathrm{nT}_{\mathrm{f}} \mathrm{h}_{\mathrm{f}} / \mu \mathrm{J}_{\mathrm{f}}^{2}, \\
& \mathrm{~A}=\left(4 \mathrm{C} \sigma_{\mathrm{f}} \mathrm{T}_{\mathrm{f}} \mathrm{n}^{\gamma} / \mathrm{J}_{\mathrm{f}}^{2}\right) \frac{\mathrm{h}_{\mathrm{f}}^{(\mathrm{p}-\mathrm{s}+1)}}{\left(\pi \mathrm{J}_{\mathrm{f}}\right) \mathrm{p}_{\mathrm{T}}^{\mathrm{q} / 2}},
\end{aligned}
$$

and $S(\rho)$ is defined by

$$
\chi r \frac{\partial T}{\partial r}=2 C\left[n^{\gamma} h_{f}^{(p-s)} T_{f}^{(q / 2-1)} /\left(\pi J_{f}\right)^{p}\right](t / \tau)^{-(1+2 \alpha) / 5} S(\rho)
$$


We also have

$$
\frac{d G}{d \rho}=S G^{q / 2} Z^{p} / \rho^{s+1}
$$

In order to satisfy the self-consistency, one should include the electric field diffusion equation, Eq. (1), which can be expressed in terms of $t$ and $\rho$ as

$$
\frac{1}{J} \frac{\partial J}{\partial \rho}-\frac{1}{\sigma} \frac{\partial \sigma}{\partial \rho}=\frac{\sigma}{2 \rho J}\left[\frac{\partial}{\partial t}\left(\mathrm{rB}_{\mathrm{p}}\right)+\frac{\rho}{\mathrm{h}} \frac{\partial \mathrm{h}}{\partial \mathrm{t}} \frac{\partial}{\partial \rho}\left(\mathrm{rB}_{\mathrm{p}}\right)\right]
$$

Using Eqs. (10), (11), (15), (23), and (33) in Eq. (39), we find

$\rho \frac{\mathrm{dF}}{\mathrm{d} \rho}=\frac{3}{2} \mathrm{FSG}(\mathrm{q} / 2-1) \mathrm{Z}^{\mathrm{P} / \rho^{\mathrm{s}+1}}+\frac{\mathrm{G}^{3 / 2}}{2}\left[\left(\frac{2-\alpha}{10 \alpha}\right) \mathrm{Z} / \rho-\left(\frac{1-3 \alpha}{5 \alpha}\right) \mathrm{F}\right]$.

Before leaving this section we may briefly conclude that having invoked the separation of variables, we have reduced Eqs. (1)-(5) to a new set of equations in terms of one variable, $\rho$; the new set is Eqs. (12), (34), (38), and (40). This nonlinear set of equations can easily be solved by numerical techniques. ${ }^{2}$

In order to complete the scheme, the boundary and the initial conditions must be added to the set. From Eqs. (10), (11), (33), and (37) $\rho=0$ (i.e., $r=0$ ), $F(0)=1, Z(0)=0, G(0)=1$, and $S(0)=0$ since the heat flux has to vanish on the major axis. At the boundary of the torus, $r=a$, we assume that $T(r=a, t)=T_{0}$, which implies that

$$
G\left(\rho_{a}\right)=\left(\frac{T_{0}}{T_{f}}\right)\left(\frac{t}{\tau}\right)^{-2(1+2 \alpha) / 5}
$$

where $\rho_{a}=a^{2} h(t)$. At an initial time, say at time $t=t_{0}$, we begin the discharge and assume $T\left(t=t_{0}, r=0\right)=T_{0}$. Thus, from Eq. (33), we get

$$
t_{0}=\tau\left(\frac{T_{0}}{T_{f}}\right)^{5 / 2(1+2 \alpha)}
$$

and therefore the solutions are valid for $t>t_{0}$. 


\section{CALCULATION OF PLASMA PARAMETERS}

The plasma parameters can now be evaluated in terms of the characteristic parameters of the system, e.g., $\alpha, h_{f}$, and D. First, it is convenient for the calculation to define $B_{f}$ and $T_{B}$ as

$$
\begin{aligned}
& B_{f} \equiv B_{p}(r=a, t=\tau)=\mu I_{f} / 2 \pi a, \\
& T_{B} \equiv B_{f}^{2} / 4 \mu n .
\end{aligned}
$$

The plasma discharge parameters may then be computed.

(1) The initial poloidal beta, $\beta_{p_{0}}$, is

$$
\beta_{p_{0}} \equiv \frac{2 \pi T_{o}}{B_{f}^{2} / 2 \mu}=\frac{16 \pi T_{f}{ }^{2} h_{f}^{2} G_{f}}{\mu J_{f}^{2} Z_{f}^{2}}=\frac{T_{o}}{T_{B}}
$$

where $z_{f} \equiv Z\left(\rho_{f}\right), G_{f} \equiv G\left(\rho_{f}\right)$, and $\rho_{f} \equiv \rho(r=a, t=\tau)=a^{2} h_{f}$.

(2) The averaged poloidal beta, $\bar{\beta}_{p}$, is

$$
\bar{\beta}_{p} \equiv \frac{2 \mathrm{n} \int_{0}^{a} 2 \pi r d r T(r, t=\tau)}{\left(B_{f}^{2} / 2 \mu\right) \pi a^{2}}
$$

or

$$
\begin{aligned}
& \bar{\beta}_{\mathrm{p}} / \beta_{p_{0}}=\int_{0}^{\rho} \mathrm{f} d \rho G(\rho) / \rho_{f} G_{f} . \\
& \text { (3) The safety factor, } q_{g} \text {, is } \\
& q_{S}=\left(r / R_{o}\right)\left(B_{T} / B_{p}\right)=\left(2 \pi r^{2} / R_{o}\right) B_{T} / \mu I,
\end{aligned}
$$

where $B_{T}$ is the toroidal magnetic field and $R_{0}$ is the major radius of the torus. Hence we find from Eq. (11) 


$$
q_{s}(r, t) / q_{s}(r=0, t)=\frac{\rho}{Z(\rho)}\left(\frac{t}{\tau}\right)^{-\alpha},
$$

and therefore

$$
q_{b} \equiv q_{s}(r=a) / q_{s}(r=0)=\rho_{f} / z_{f}
$$

(4) The poloidal flux function, $\psi$, is

$$
\psi=R_{0} \int_{0}^{r} d r^{\prime} B_{p},
$$

and because

$$
\frac{\partial \psi}{\partial \mathrm{r}} \frac{\mathrm{q}}{\mathrm{r}} \simeq \mathrm{B}_{\mathrm{T}}
$$

we find from Eqs. (7) and (11)

$$
\begin{aligned}
& \psi(r, t)=\mu R_{0} \frac{J_{f}}{4 h_{f}}\left(\frac{t}{\tau}\right)^{(2-\alpha) / 5} \cdot \int_{0}^{\rho} d \rho^{\prime} z\left(\rho^{\prime}\right) / \rho^{\prime} . \\
& \text { (5) The skin time, } \tau_{s} \text {, is } \\
& \frac{1}{{ }^{\prime} s} \equiv \frac{1}{\psi} \frac{\partial \psi}{\partial t}=\frac{\partial}{\partial t} \ln \psi .
\end{aligned}
$$

Thus we get

$$
\frac{1}{\tau_{S}}=\frac{2-\alpha}{5 t}+\rho \frac{\partial}{\partial t} \ln \cdot h \frac{d / d \rho \int_{0}^{\rho} \mathrm{d} \rho^{\prime} Z\left(\rho^{\prime}\right) / \rho^{\prime}}{\int_{0}^{\rho} \mathrm{d} \rho^{\prime} Z\left(\rho^{\prime}\right) / \rho^{\prime}} .
$$

Substituting Eq. (23) into the above gives 
$\tau / \tau_{s}=\frac{\tau}{5 t}\left[(2-\alpha)-\frac{2(1-3 \alpha) Z(\rho)}{\int_{0}^{\rho} \mathrm{d} \rho^{\prime} Z\left(\rho^{\prime}\right) / \rho^{\prime}}\right]$.

(6) The electron energy lifetime, $\tau_{E}$, is

$$
\tau_{E}(r)=\frac{\int_{0}^{r} \frac{3}{2} n T\left(r^{\prime}, t=\tau\right) r^{\prime} d r^{\prime}}{\int_{0}^{r} \frac{J^{2}\left(r^{\prime}, t=\tau\right)}{\sigma\left(r^{\prime}, t=\tau\right)} r^{\prime} d r^{\prime}}
$$

Using Eqs. (10) and (33) in Eq. (51), for $t=\tau$ we get

$$
\tau_{E}(r) / \tau_{E_{f}}=\frac{\int_{0}^{\rho} \mathrm{d} \rho^{\prime} G\left(\rho^{\prime}\right)}{\int_{0}^{\rho} \mathrm{d} \rho^{\prime} F^{2}\left(\rho^{\prime}\right) / G^{3 / 2}\left(\rho^{\prime}\right)} .
$$

Here, we have $\tau_{E_{f}} \equiv W_{f} / P_{\Omega}$, where $W_{f} \equiv \frac{3}{2} n T_{f}$ and $P_{\Omega} \equiv J_{f}^{2} / \sigma_{f}$.

(7) The transformer flux, $\psi_{t r}$, is a flux function related to the electric field at the transformer coils, $\mathrm{r}=\mathrm{b}$, by the relation

$$
2 \pi R_{o} E(r=b, t)=\frac{\partial}{\partial t} \psi_{t r} .
$$

We compute $\psi_{t r}$ for $t=\tau$, that is,

$$
\begin{aligned}
& \psi_{t r}(L-v, L=\tau)=2 \pi R_{0} \int_{t_{0}}^{\tau} d t\left[E(0, t)+\int_{r}^{b} \frac{d r^{\prime}}{r^{\prime}} \frac{\partial}{\partial t}\left(r^{\prime} B\right)\right] \\
& \equiv 2 \pi R_{0}\left(\psi_{1}+\psi_{2}\right) \text {. }
\end{aligned}
$$

The first time integration in Eq. (53) becomes 


$$
\psi_{1}=\frac{J_{f}}{\sigma_{f}} \frac{5 \tau}{(2-\alpha)}\left[1-\left(t_{o} / \tau\right){ }^{(2-\alpha) / 5}\right],
$$

and the second integration is

$$
\psi_{2}=\mu \frac{J_{f}}{4 h_{f}}\left[2 z_{f} \ln (b / a)+\int_{0}^{\rho_{f}} \mathrm{~d} \rho \mathrm{Z}(\rho) / \rho\right] .
$$

Finally, making use of Eqs. (27) and (42) in $\psi_{1}$ and $\psi_{2}$, we obtain

$$
\begin{aligned}
\frac{\psi_{t r}}{\mu R_{o} I_{f}}=\frac{10 \alpha}{(2-\alpha) Z_{f}}\left[1-G_{f}^{(1-\alpha / 2) /(1+2 \alpha)}\right] & +[\ln (b / a) \\
& \left.+\frac{1}{2 Z_{f}} \int_{0}^{\rho_{f}} \mathrm{~d} \rho Z(\rho) / \rho\right] .
\end{aligned}
$$

Here $I_{f} \equiv I(r=a, t=\tau)=\pi J_{f} Z_{f} / h_{f} \cdot$ 


\section{DISCUSSIONS AND AN APPLICATION OF THE RESULTS}

Some well-known scaling laws for $x$ may be obtained by inspection of Eqs. (9) and (30). For various values of $s$, Table 1 is obtained when $\chi=\chi(s, p, q, \gamma=0)$. As we see from the table, the pseudoclassical scaling is

$$
x(s=1, q=1, p=2) \equiv x^{P S} \sim \frac{1}{T^{1 / 2} B_{p}^{2}} \sim \nu_{e i} \rho_{p_{e}}^{2},
$$

where $\rho_{\mathrm{P}_{e}}$ is the Larmor radius and $\nu_{e i}$ is the collistur frequellcy of lie electrons. As $r$ approaches zero, $X^{P S}$ diverges. That can be avoided by introducing

$$
x^{M} \equiv\left(\frac{r}{a}\right)^{2} \chi^{P S}=\chi(s=2, q=1, p=2),
$$

which is known as the Mercier ${ }^{3}$ scaling. In this case $\alpha$ turns out to be $1 / 3$, which has also been suggested by Jensen. 4

\begin{tabular}{|c|c|c|c|c|}
\hline$u$ & $s$ & 4 & $p$ & $x$ \\
\hline Arb1erary & 0 & 3 & 0 & $1 / \mathrm{T}^{2 / 2}$ (nevelassical) \\
\hline Arbitrary & 1 & 1 & 2 & $x^{2} / I^{2} T^{1 / 2}$ (pspudar1assira1) \\
\hline $1 / 3$ & 2 & 1 & 2 & $\mathrm{r}^{4} / \mathrm{I}^{2} \mathrm{~T}^{1 / 2}$ (Mercier-1ike) \\
\hline
\end{tabular}

Table 1. The heat conductivity coefficient, $X=\mathrm{Cn}^{\gamma} \mathrm{r}^{2 \mathrm{~s}} / \mathrm{I}_{\mathrm{T}} \mathrm{p}^{\mathrm{q} / 2}$

We now discuss the coefficient $s$ which is refined by Eq. (9). As we see, $C$ is a dimensional quantity. We may compute this for two cases, pseudoclassical and Mercier scaling.

With pseudoclassical scaling, $s=1, q=1$, and $p=2$. Thus, for $\gamma=0$, we have 


$$
x^{P S}=C^{P S} \frac{r^{2}}{I^{2} T^{1 / 2}}=C_{0} \nu_{e i} \rho_{P_{e}}^{2}
$$

Using

$$
\sigma=2 \frac{\mathrm{ne}^{2}}{\mathrm{mv}}=\mathrm{kT}^{3 / 2}
$$

we get

$$
c^{P S}=c_{o}\left(\frac{4 \pi}{\mu}\right)^{2} \frac{n}{k}
$$

where $C_{0}$ is a constant. For this case, Eqs. (35) and (36) become

$$
\begin{aligned}
& D=\left(\frac{6 n}{\mu a^{2}}\right) \frac{T_{f} \rho_{f}}{5 J_{f}^{2}}\left(\frac{1+2 \alpha}{\alpha}\right), \\
& A=C_{o}\left(\frac{10}{3} D \frac{\alpha}{1+2 \alpha}\right)^{2} .
\end{aligned}
$$

For Mercier scaling, since

$$
x^{M}=\left(\frac{r}{a}\right)^{2} x^{P S}
$$

we get $\mathrm{C}^{\mathrm{M}} \equiv \dot{\mathrm{C}}^{\mathrm{PS}} / \mathrm{a}^{2}$ and

$$
A=c_{o}\left(\frac{2}{3} D\right)^{2} / \rho_{f}
$$

The conventional values for $C_{0}$ in the case of pseudoclassical scaling are ${ }^{5}$

$$
C_{0}=\left\{\begin{array}{l}
10, \text { Artsimovich } \\
10, \text { Oak Ridge National Laboratory } \\
1-4, \text { Princeton Plasma Physics Laboratory. }
\end{array}\right.
$$


However, for Mercier's scaling, the value of $C_{0}$ depends on the aspect ratio, $\varepsilon=a / R_{0}$, by the relation 6

$$
\begin{array}{ll}
\mathrm{C}_{0}=2000, & \varepsilon \leqslant 0.2 \\
\mathrm{C}_{0}=2000\left(\frac{0.2}{\varepsilon}\right)^{2}, & \varepsilon>0.2 .
\end{array}
$$

It should be noted that elementary tokamak MHD stability theory requires $q_{s}(r=a) \gtrsim 2.5$ at the equilibrium $(t=\tau)$ and $\bar{\beta}_{p} \lesssim\left(R_{0} / a\right)$. These constraints must be satisfied in order to overcome the unstable operations due to the kink and ballooning modes.

Before applying the results of the separation of variables technique to an example, we should mention that it is convenient for the numerical calculations to work with $q_{b}, \beta_{p_{o}}$, and $n$, which is given by

$$
n=\left(\tau-t_{0}\right) / \tau_{B},
$$

where

$$
\begin{aligned}
& \tau_{B}=\tau\left(T_{B} / T_{f}\right)^{3 / 2} \rho_{f} / \alpha \\
& \text { Assuming } t_{o} / \tau \ll 1 \text {, the system parameters then become } \\
& \rho_{f}=\left[\frac{\alpha}{n}\left(\frac{40}{3} \frac{\alpha}{1+2 \alpha} D\right)^{3 / 2} q_{b}^{3}\right]^{2 / 5}, \\
& G_{f}=\frac{3}{40} \beta_{p_{o}}\left(\frac{1+2 \alpha}{\alpha}\right) \frac{\rho_{f}}{D_{f}^{2}},
\end{aligned}
$$

and

$$
\beta_{P_{o}} / G_{f}=T_{f} / T_{B} .
$$


The last expression yields

$$
\mathrm{T}_{\mathrm{f}}=\frac{40}{3} \frac{\alpha}{(1+2 \alpha)} \frac{\mathrm{D}}{\rho_{\mathrm{f}}} \mathrm{q}_{\mathrm{b}}^{2} \mathrm{~T}_{\mathrm{B}}
$$

To illustrate the results, a plasma sized for The Next Step (TNS) is chosen. The typical values for the device are: $R_{0}=6 \mathrm{~m}, a=1.25 \mathrm{~m}$, $\mathrm{b}=1.5 \mathrm{~m}, \mathrm{q}_{\mathrm{s}}(\mathrm{r}=\mathrm{a}, \mathrm{t}=\tau)=4, \mathrm{n}=6 \times 10^{19} \mathrm{~m}^{-3}$, and $\mathrm{B}_{\mathrm{T}}=8 \mathrm{~T}$. The computation is carried out for pseudoclassical and Mercier's scaling. The system parameters used for the calculations are $\beta_{p_{0}}=5 \times 10^{-3}$ and $\eta=5 \times 10^{-3}$. Figures $1-7$ present the results of the computation for $J(r, t) / J_{f}, T(r, t) / T_{f}, q_{s}(r, t) / q_{s}(r=0, t), x(r, t), I_{p}(t) / I_{f}$ (where $I_{p}$ is the plasma current), $\tau / \tau_{s}(t)$, and $\psi(r=a, t)$. Each figure shows the results for both pseudoclassical (a) and Mercier (b) scaling. Other plasma parameters from the computation are summarized in Table 2 .

Table 2. The results of the discharge parameters for TNS-size plasma

\begin{tabular}{lll}
\hline & \multicolumn{2}{c}{ Scaling } \\
\hline$\alpha$ & $10^{-2}$ & Mercier \\
\hline$T_{f}(\mathrm{keV})$ & 3.4 & $1 / 3$ \\
$\mathrm{~T}_{\mathrm{o}}(\mathrm{eV})$. & 18 & 2.79 \\
$\mathrm{I}_{\mathrm{f}}(\mathrm{kA})$ & 2600 & 18 \\
$\tau(\mathrm{sec})$ & 2.38 & 2600 \\
$\tau_{\mathrm{s}}(\mathrm{sec})$ & 10.48 & 2.38 \\
$\tau_{\mathrm{E}}(\mathrm{r}=\mathrm{a})(\mathrm{sec})$ & 1.46 & 7.14 \\
$\bar{X}^{2}\left(\mathrm{~m}^{2} / \mathrm{sec}\right)$ & 0.138 & 0.364 \\
$\bar{B}_{\mathrm{p}}(\mathrm{V}-\mathrm{sec})$ & 0.226 & 26.95 \\
$\psi_{\mathrm{tr}}$ & 27.82 & 0.122 \\
$\mathrm{C}_{\mathrm{o}}$ & 10 & 31.15 \\
\end{tabular}



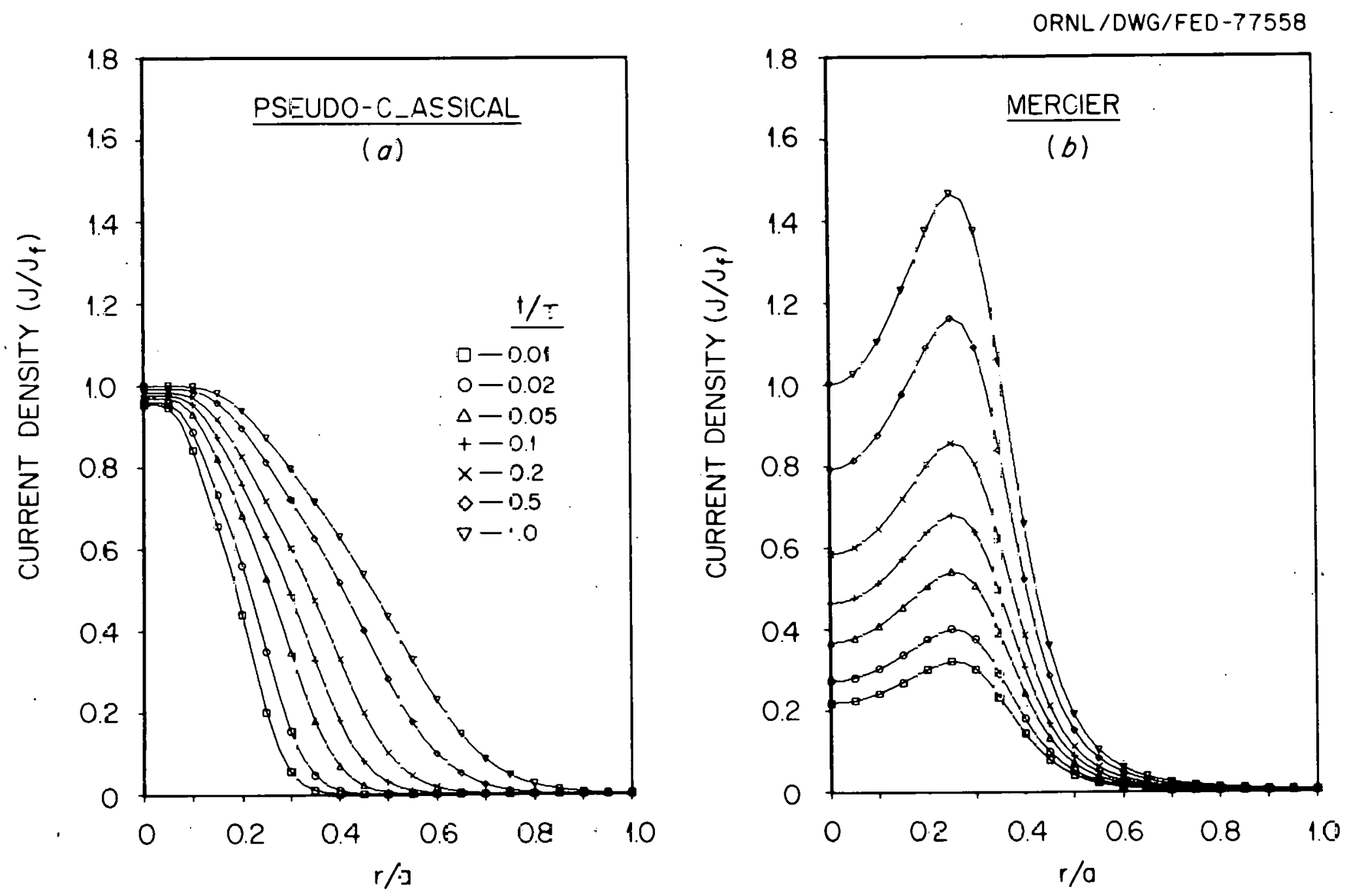

Fig. 1. Time evolution of the radial profiles of the current density, $J(r, t) / J_{f}$. 
ORNL / DWG / FED - 77557
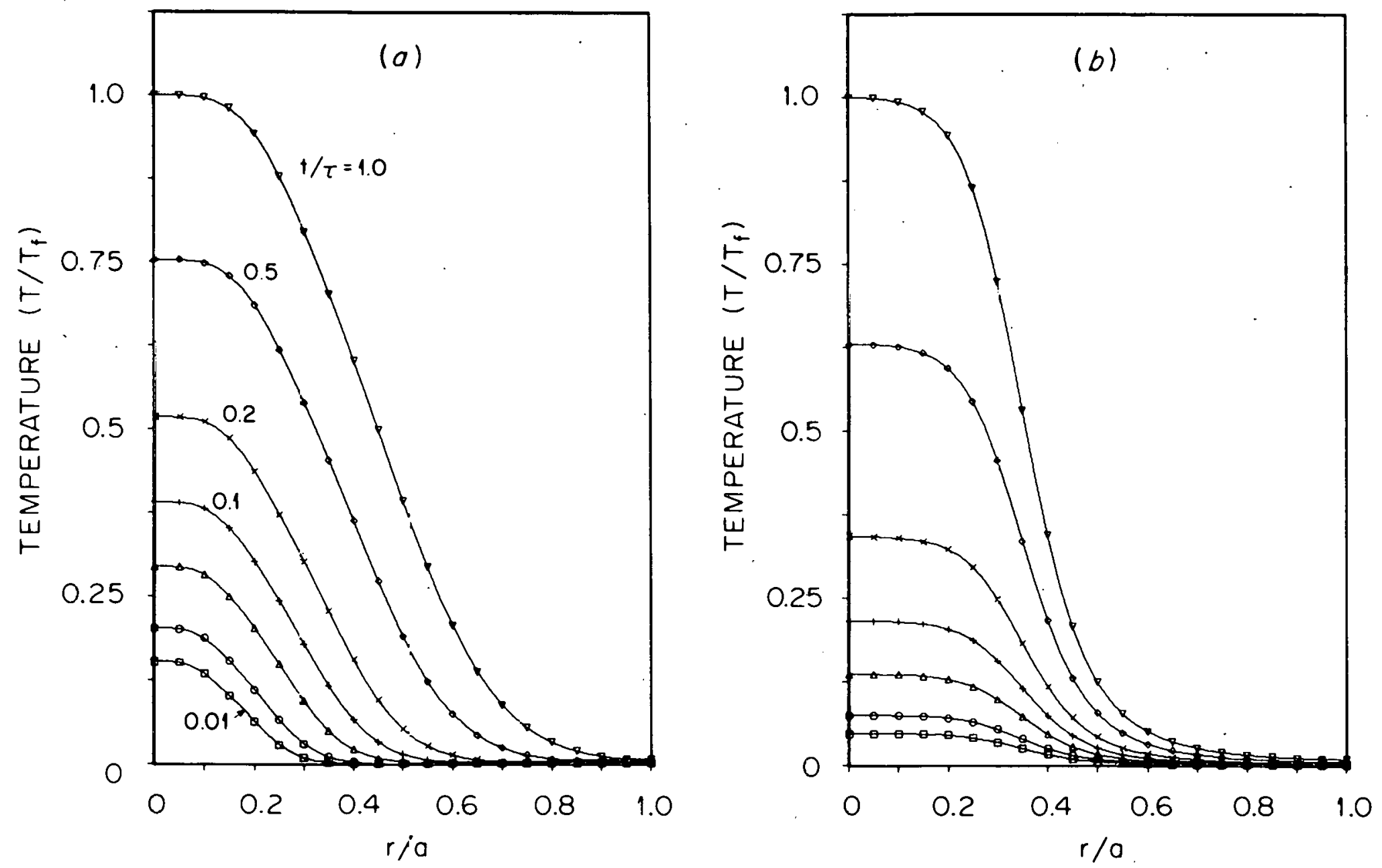

Fig. 2. Tine evolution of the temperature profiles, $T(r, t) / T_{f}$. 

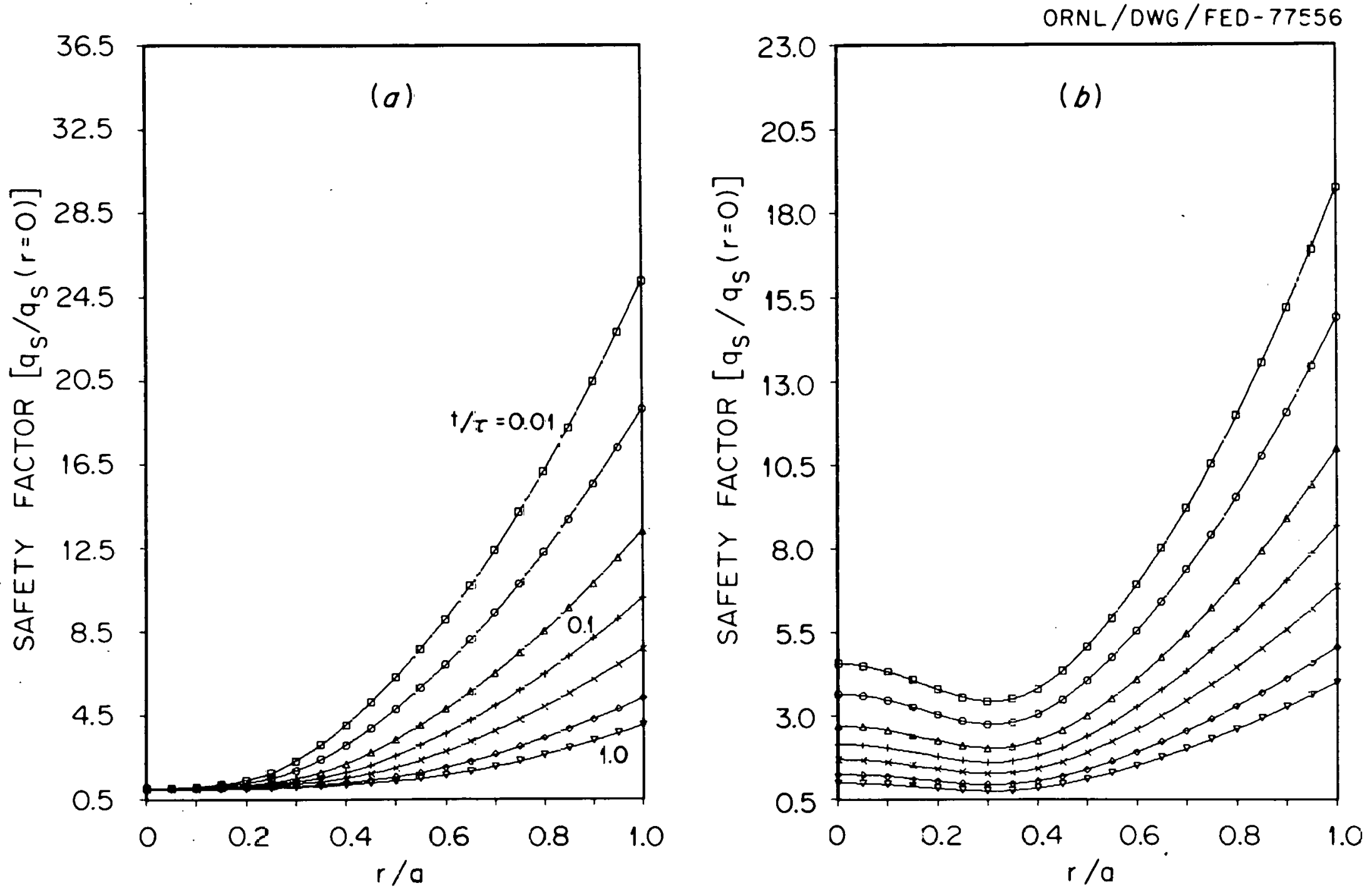

Fig. 3. Time evolution of the normalized safety factor, $q_{s}(r) / q_{s}(0)$. 
ORNL / DWG / FED - 77555
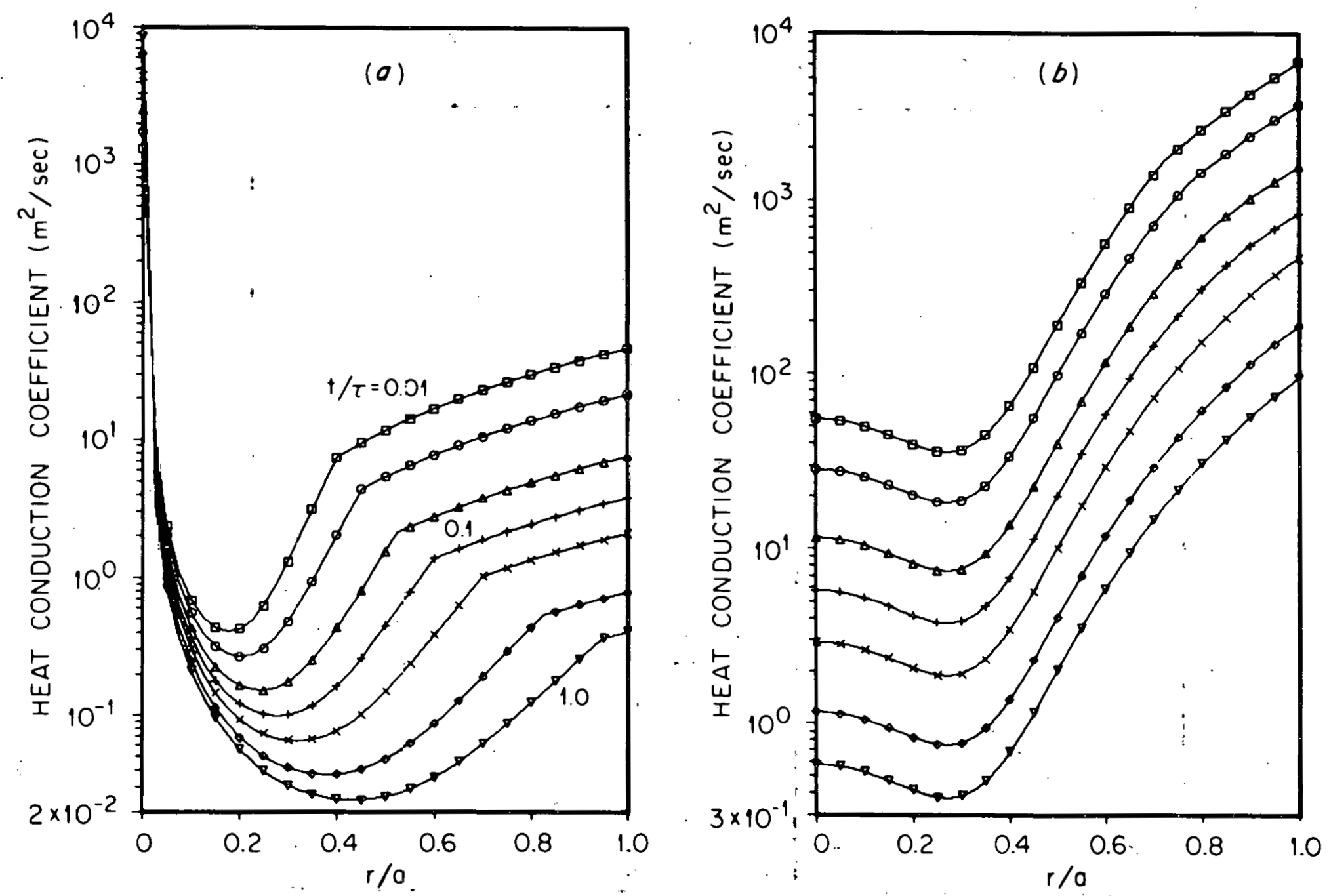

Fig. 4. Evolution of the heat conductivity coefficient, $\chi(r, t)$. 
ORNL / OWG/FED-?7554
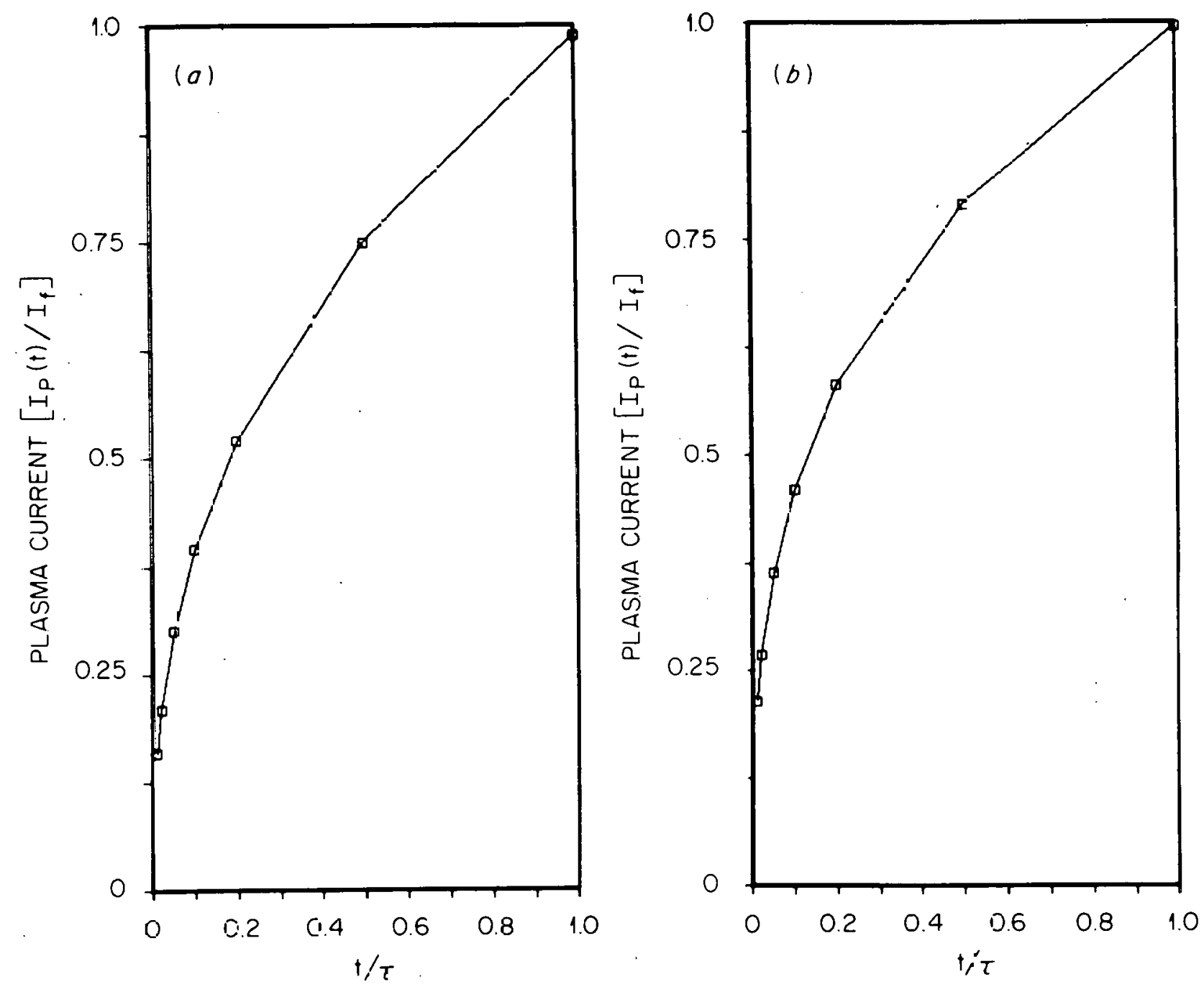

Fig. 3. Evolution of the plasma current, $I_{p}(t) / I_{E^{*}}$. 
ORNL /DWG/FED -77553
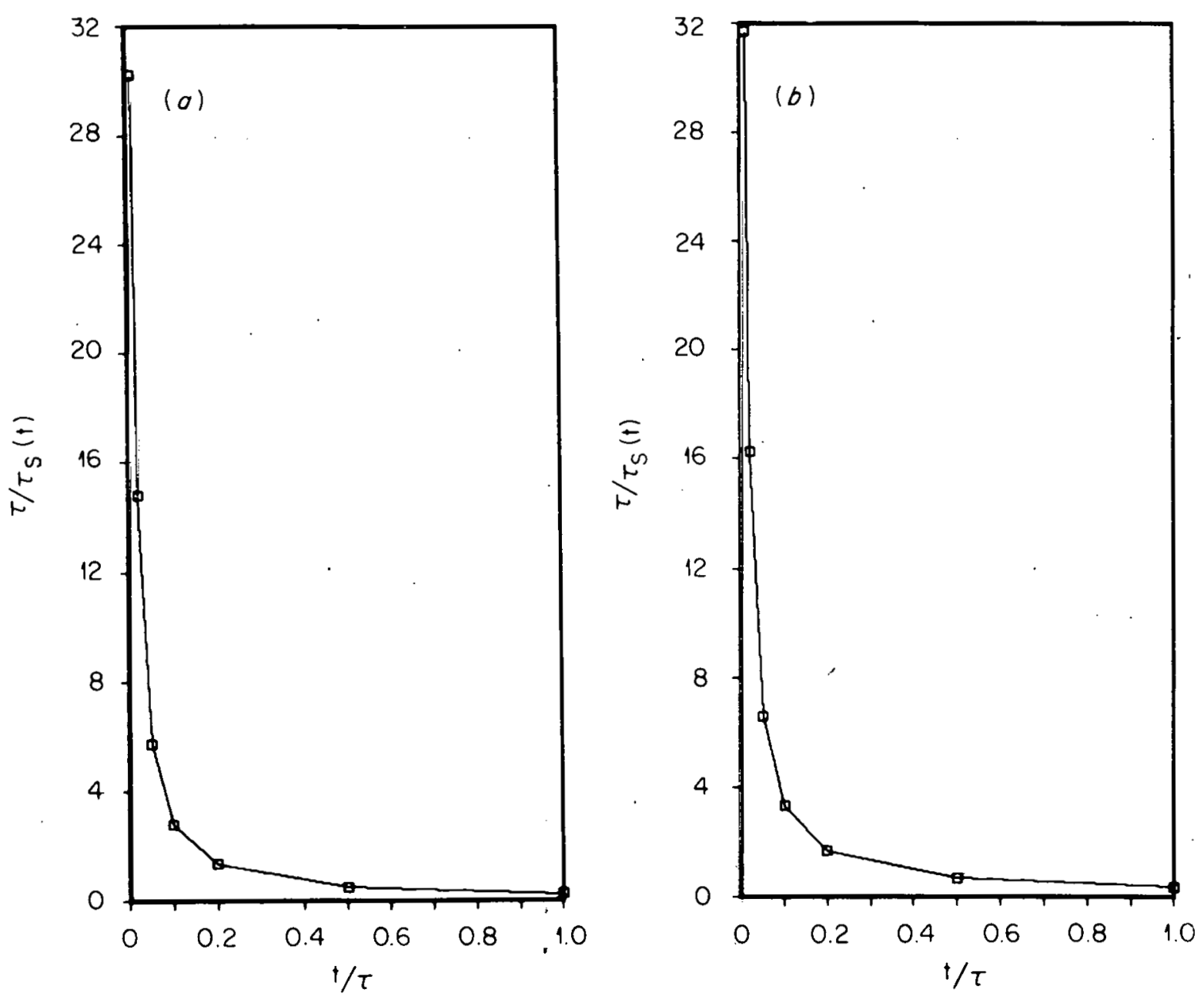

Fig. 6. Evolution of the normalized skin time at the edge, $\tau / \tau_{s}(t)$. 
ORNL I DWG/FED-77552
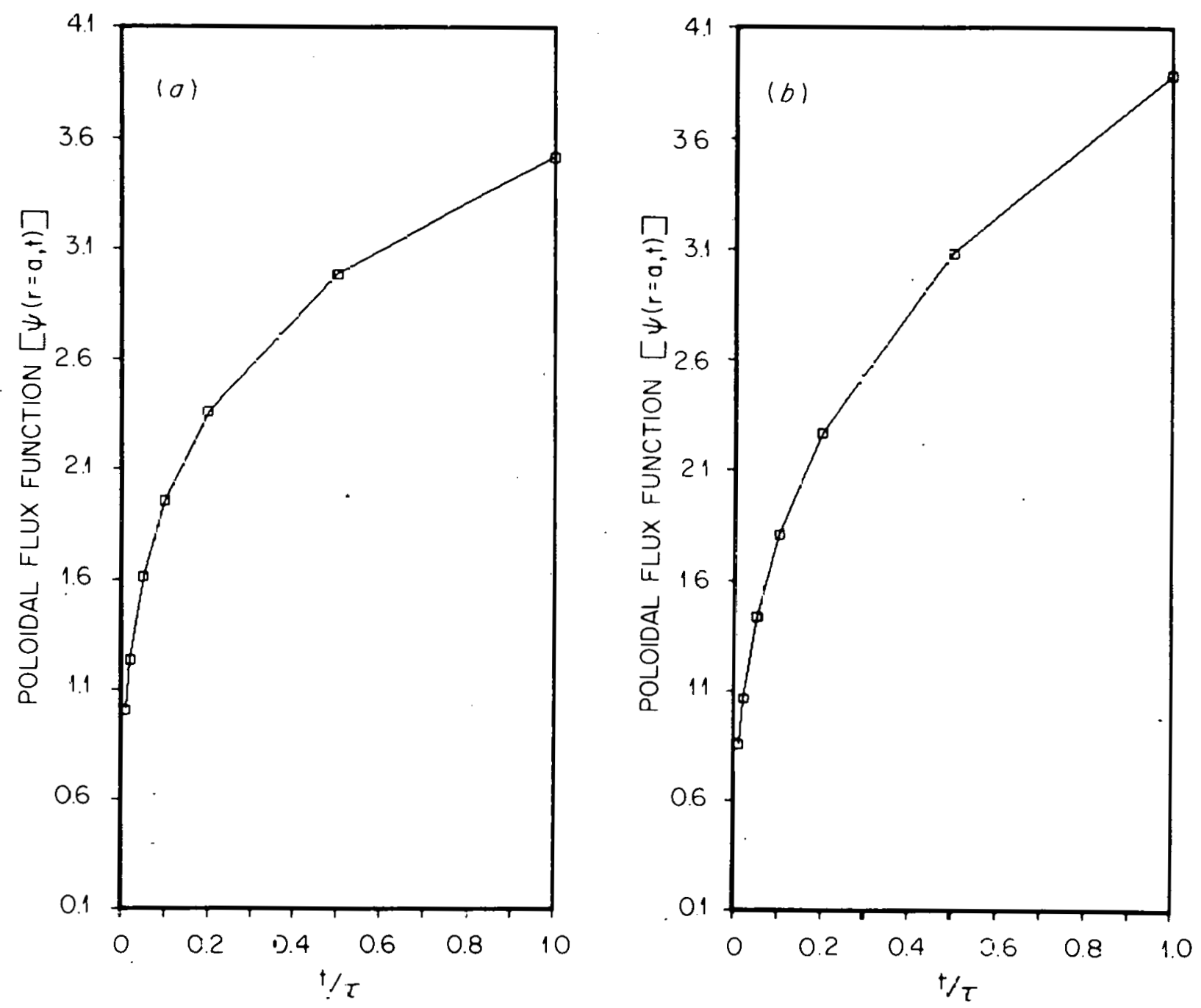

Fig. 7. Evolution of the poloidal flux function at the edge, $\psi(a, t)$. 


\section{REFERENCES}

1. L. Enriques and F. Santini, Nuovo Cimento B $\underline{25}, 842$ (1975).

2. For example, a fourth-order Runge-Kutta routine may be used.

3. C. Mercier, Transport in Tokamak Plasmas, EUR-CEA-FC-812, Commission de I'Energie Atomique (1976).

4. T. H. Jensen, Phys. Fluids 20, 427 (1977).

5. S. 0. Dean, Status and Objectives of Tokamak Systems for Fusion Research, WASH-1295, United States Atomic Energy Commission, Washington, D.C. (1974).

6. C. Mercier, Plasma Buildup by a Moving Limiter in the JET, EUR-CEA-FC-742, Commission de I'Energie Atomique (1974). 
THIS PAGE

\section{WAS INTENTIONALLY}

LEFT BLANK 
ORNL/TM-6065

\section{INTERNAL DISTRIBUTION}

\author{
1. L. A. Berry \\ 2. J. D. Callen \\ 3. R. A. Dand 1 \\ 4. R. A. Dory \\ 5. W. A. Houlberg \\ 6. H. C. Howe \\ 7. G. G. Kelley \\ 8. A. T. Mense \\ 9. 0. B. Morgan \\ 10. Y-K. M. Peng
}

\author{
11. M. W. Rosentha1 \\ 12-36. T. Uckan \\ 37-39. Laboratory Records Department \\ 40. Laboratory Records - ORNL-RC \\ 41. Y-12 Document Reference Section \\ 42-43. Central Research Library \\ 44. Fusion Energy Division Library \\ 45. Fusion Energy Division Reports \\ Office \\ 46. ORNL Patent Office
}

\section{EXTERNAL DISTRIBUTION}

47. Plasma Physics Library, Plasma Physics Laboratory, Princeton University, Forrestal Campus, P.0. Box 451, Princeton, NJ 08540

48. Controlled Thermonuclear Research Library, Lawrence Livermore Laboratory, P.0. Box 808, Livermore, CA 94550

49. Q Division Library, Los Alamos Scientific Laboratory, P.0. Box 1663, Los Alamos, NM 87544

50. CTR Computer Center, c/o John Killeen, Lawrence Livermore Laboratory, P.0. Box 808, Livermore, CA 94550

51. Librarian, Culham Laboratory, U.K. Atomic Energy Authority, Abingdon, Oxon, OX14 3DB, United Kingdom

52. Ruth Lengye, Bibliothek, Max-Planck Institut für Plasmaphysik, 8046 Garching bei München, Federal Republic of Germany

53. Library, Centre de Recherches en Physique des Plasmas, 21 Avenue des Bains, 1007, Lausanne, Switzerland

54. A. M. Dupas, Documentation S.I.G.N., Départment de la Physique du Plasma et de la Fusion Controlée, Association EURATOM-CEA sur la Fusion, Centre d'Etudes Nucleaires, B.P. 85 Centre Du TRI 38041 Grenoble Cedex (France)

55. Bibliothéque, Service du Confinement des Plasmas, C.E.A., B.P. No. 6, 92, Fontenay-aux-Roses (Seine) France

56. Library, International Centre for Theoretical Physics, Trieste, Italy

57. Library, Laboratorio Gas Ionizzati, Frascati, Italy

58. V. E. Ivanov, Physical-Technical Institute of the Ukranian Academy of Sciences, Sukhumi, U.S.S.R.

59. L. M. Kovrizhnikh, Lebedev Institute of Physics, Academy of Sciences of the U.S.S.R., Leninsky Prospect 53, Moscow, U.S.S.R.

60. Dshumber G. Lominadze, Academy of Sciences of the Georgian SSR, 8 Dzerzhinsk1 SL., 38004, Tbilisi, U.S.S.R.

61. Library, Institute for Plasma Physics, Nagoya University, Nagoya, Japan 464

62. Library, FOM-Institut voor Plasma-Fysica, Rijnhuizen, Jutphaas, Netherlands

63. Plasma Physics Group, Department of Engineering Physics, Australian National University, P.O. Box 4, Canberra A.C.T. 2600, Australia 
64. Thermonuclear Library, Japan Atomic Energy Research Institute, Tokai, Naka, Ibaraki, Japan

65. D. G. McAlees, Exxon Nur1par $\mathrm{.o.,}$ Inc., Rcocarch \& Tecluulugy Laser Enrichment Department, 2955 George Washington Way, Richland, WA 99352

66. CTR Reading Room, c/o D. W. Kerst, Dept. of Physics, Sterling Hall, University of Wisconsin, Madison, WI 53706

67. CTR Reading Room, c/o I. B. Bernstein, Yale University, 200 Mason Laboratory, Dept. of Engineering \& Applied Science, New Haven, CT 06510

68. Center for Plasma Physics and Thermonuclear Research, c/o D. W. Ross, Physics Dept., University of Texas, Austin, TX 78712

69. CTR Reading Room, c/o B. D. Fried, Physics Dept., University of California, Los Angeles, CA 90024

70. CTR Reading Room, c/o David C, Montgomery, Physics \& Astronomy Depl., Unlversity of lowa, Iowa City, IA 52.240

71. Magneto-Fluid-Dynamics Library, c/o Harold Grad, Courant Inst. of Math. Sc1., New York University, 251 Mercer St., New York., NY 1001:

72. L'IK Keading Room, c/o Allan N. Kaufman, Physics Dept., University of California, Berkeley, CA 94720

73. CTR Reading Room, c/o C. S. Liu, Dept. of Physics and Astronomy, University of Maryland, College Park, MD 20742

74. CTR Reading Room, c/o T. Kammash, 103 Research Admin. Bldg., N. Campus, University of Michigan, Ann Arbor, MI 48105

75. CTR Reading Room, c/o Ravi N. Sudan, Phillips Hall, Cornell University, Ithaca, NY 14850

76. Marshall N. Rosenbluth, Institute for Advanced Study, Princeton, NJ 08540

77. CTR Reading Room, c/o R. Gross, Plasma Research Laboratory, Columbia University, New York, NY 10027

78. CTR Reading Room, c/o Roy Gould, California Institute of Technology, M.S. 116-81, Pasadena, CA 91125

79. Nicholas A. Kra11, Science Applications, Inc., P.0. Box 2354, 1200 Prospect St., La Jolla, CA 92037

80. CTR Reading Room, c/o Jay P. Boris, Plasma Physics, Naval Research Laboratory, Washington, DC 20390

81. A. Simon, Dept. of Mechanical \& Aerospace Sciences, University of Rochester, Rochester, NY 14627

82. CTR Library, c/o Alan F. Haught, United Technologies Research Laboratories, East Hartford, CT. 06108

83. H. K. Forsen, Exxon Nuclear Co., Inc., 777-106th Avenue, NE, C-000777, Bellevue, WA 98009

84. J. F. Clarke, Division of Magnetic Fusion Energy, G-234, Department of Energy, Washington, DC 20545

85. R. E. Price, Division of Magnetic Fusion Energy, G-234, Department of Energy, Washington, DC 20545

86. R. C. Davidson, Division of Magnetic Fusion Energy, G-234, Department of Energy, Washington, DC 20545

87. 0. P. Manley, Division of Magnetic Fusion Energy, G-234, Department of Energy, Washington, DC 20545 
88. E. E. Kintner, Division of Magnetic Fusion Energy, G-234, Department of Energy, Washington, DC 20545

89. L. D. Pearlstein, L-388, Lawrence Livermore Laboratory, P.0. Box 808, Livermore, CA 94550

90. David J. Rose, Dept. of Nuclear Engineering, Massachusetts Institute of Technology, Cambridge, MA 02139

91. Gareth E. Guest, General Atomic Co., P.0. Box 81608, San Diego, CA 92138

92. Claude Mercier, Service du Theorie des Plasmas, Centre d'Etudes Nucleaires, Fontenay-aux-Roses (Seine) France

93. J. B. Taylor, Culham Laboratory, UKAEA, Abingdon, Oxon, OX14 3DB, United Kingdom

94. D. Pfirsch, Institute for Plasma Physics, 8046 Garching bei München, Federal Republic of Germany

95. V. D. Shafranov, I. V. Kurchatov Institute of Atomic Energy, 46 Ulitsa Kurchatova, P.0. Box 3402, Moscow, U.S.S.R.

96. J. G. Cordey, Culham Laboratory, UKAEA, Abingdon, Oxon, 0X14 3DB, United Kingdom

97. David Baldwin, L-388, Lawrence Livermore Laboratory, P.0. Box 808, Livermore, CA 94550

98. CTR Reading Room, c/o Bruno Coppi, Dept. of Physics, MIT, Cambridge, MA 02138

99. H. P. Furth, Plasma Physics Laboratory, Princeton University, P.O. Box 451, Princeton, NJ 08540

100. Research and Technical Support Division, Oak Ridge Operations, Department of Energy, P.O. Box E, Oak Ridge, TN 37830

101-127. Technical Information Center, P.0. Box 62, Oak Ridge, TN 37830 